\title{
Urinary Tract Infection in Pregnancy and its Correlation with Nitrite Test
}

\author{
Subedi $M,{ }^{1}$ Basnyat $S R,{ }^{2}$ Acharya $\mathrm{SD}^{3}$ \\ 'Department of Microbiology, Amrit Science Campus, Kathmandu, ${ }^{2}$ Central Department of Microbiology, TU, Kirtipur, \\ ${ }^{3}$ Lumbini Zonal Hospital, Butwal.
}

\section{ABSTRACT}

Background: Urinary Tract Infection is one of the most frequently seen medical complications of pregnant women. The value of screening for bacteriuria by rapid test has to be readdressed considering methods, significance and costs. The study was done to assess the sensitivity and specificity of rapid test (nitrite test) for the confirmation of UTI and etiology of infection during pregnancy and antibiotics sensitivity pattern of the isolates.

Methods: In this observational based study, mid stream urine samples from 100 pregnant women clinically suspected of urine infection were evaluated by urine dipstick analysis, microscopic and by culture method. The isolates were identified and antibiotic sensitivity pattern was determined by standard protocol. At the end, Sensitivity, Specificities, Positive and Negative predictive values of isolates were determined from nitrite test.

Results: Out of 100 clinically suspected UTI cases, 45\% were culture positive of which (55.5\%) were Gramnegative bacteria of them Escherichia coli $(\mathrm{n}=14)$ was the most common pathogens and Staphyococcus aureus $(\mathrm{n}=11)$ was found to be predominant in Gram positive bacteria. Among total 45 positive cases, 17 samples were nitrite positive and also culture positive. The Sensitivity, Specificity, Positive and Negative predictive values of nitrite test in relation to Enterobacteriaceae were $70.8 \%, 100 \%, 100 \%$ and $91.5 \%$ respectively where as Sensitivity, Specificity, Positive and Negative predictive value of nitrite test in relation to Escherichia coli were 100\%, 96.6\%, 82.3\%, and 100\%, respectively. Amikacin as well as Gentamycin was found the most effective antibiotics against Gram negative and Gram positive bacteria.

Conclusions: Although, confirmatory diagnosis can be achieved by urine culture method, the combination of Nitrite test with pyuria appears to be rapid test and very useful markers for bacterial UTI in district laboratories where culture facilities are rare. On the basis of in vitro tests Amikacin and Ciprofloxacin are comparatively effective drugs for UTI.

Key words: antibiotics, nitrite test, pregnant women, urinary tract infection. 
Urinary Tract Infection in Pregnancy and Its Correlation with Nitrite Test

\section{INTRODUCTION}

Urinary Tract Infection (UTI) is one of the most frequently encountered problems owing to significant number of patients needing hospitalization during pregnancy. In pregnant women the incidence of UTI can be as high as $8 \%$. Similarly, $2 \%$ of 24000 patients acquired acute pyelonephritis during pregnancy. ${ }^{1}$ The report has shown that $6 \%$ of pregnant women had asymptomatic bacteriuria as well as $11.8 \%$ of bacteriuric women developed symptoms of infection in pregnancy; whereas only $3.2 \%$ of women with sterile urine did so. ${ }^{2,3}$

The diagnosis of UTIs should be based initially on the clinical aspects presented by the patient and confirmed by urine culture. However, microscopic examination of urine for the presence of pyuria with nitrite test is another available option for the rapid screening of UTI. The nitrite test is highly sensitive and specific when properly used in first morning urines whose efficiency was found to $90 \% .{ }^{4}$ Thus, A positive nitrite test with pyura is taken as highly reliable marker for bacterial UTI.

Escherichia coli is present in between 80 and $90 \%$ of UTIs and up to $95 \%$ of acute pyelonephritis ${ }^{5,6}$ and Novobiocinresistant Staphylococcus saprophyticus is the true gram positive pathogen of UTI. ${ }^{7}$

This article briefly examines the efficiency of nitrite test for UTI with culture, significant of pus cells, etiological agents for UTI in pregnant women and their antibiotic sensitivity pattern.

\section{METHODS}

An observational study was conducted in Lumbini Zonal Hospital from October 2004 to March 2005. Ethical approval was taken from institutional ethical committee. Similarly, Verbal consent was taken to all patients for fulfilling semi structured interview questionnaire. Purposive sample were selected on the basis of symptoms of increased frequency micturation, Dysurea, Uregency and Fever in clinically suspected UTI patient. All clinically suspected pregnant women of UTI, attending outpatient department and hospitalized were only included where as non pregnant women were excluded.

Mid stream urine was processed for nitrate reduction test, microscopy for pyuria, and culture. Urine culture, WBC counts and nitrite test were performed on the urine specimen. Nitrite test was performed by using two drops of two different solutions; N-1-napthylenediamine and sulphanilamide and mixed with equal amounts of urine in a kit well and observed for magenta color for positive test.
For culture, $0.001 \mathrm{ml}$ of un-centrifuged, mixed mid stream urine specimen were streaked onto Mac-Conkey agar and Blood agar plates with the help of standard flame sterilized loop. Bacterial growths were observed following overnight incubation and their sensitivity pattern were determined by Kirby-Bauer disc diffusion method. Finally, correlation between nitrite test and bacterial isolates were determined.

Statistical analysis was done by in accordance with the specific objective i.e. finding sensitivity, specificity and positive and negative predictive values of nitrite and culture. For this Microsoft excel was used.

\section{RESULTS}

Out of 100 clinically suspected pregnant women of UTI cases having different ages, 45 (45\%) were culture positive. Of that culture positive cases, age 20-30, were the highest number suffered from UTI (Table 1). Of the total suspected cases, the majority 59 (59\%) cases were multigravidae and that was the highest number suffered from UTI, 27 (60\%) in positive cases. $72 \%$ of the clinically suspected patients had increased frequency of micturition of which 22 (30.5\%) were culture positive. Based on different symptoms different diagnosed cases were found (Table 2).

\begin{tabular}{|lccc|}
\hline \multicolumn{4}{|c|}{ Table 1. Distribution of Cases according to Age } \\
\hline Age (in years) & $<20$ & $20-30$ & $>30$ \\
& No. (\%) & No. (\%) & No. (\%) \\
\hline $\begin{array}{l}\text { Total suspected } \\
\text { cases (N=100) }\end{array}$ & $35(35 \%)$ & $61(61.0 \%)$ & $4(4.0 \%)$ \\
$\begin{array}{l}\text { Total culture } \\
\text { positive cases } \\
(\mathrm{N}=45)\end{array}$ & 14 & $30(66.67 \%)$ & $1(2.22 \%)$ \\
\hline
\end{tabular}

Table 2. Distribution of cases according to symptoms

\begin{tabular}{|lcc|}
\hline \multicolumn{1}{|c}{ Symptoms } & $\begin{array}{c}\text { Total Suspected } \\
\text { cases } \\
\text { No. (\%) }\end{array}$ & $\begin{array}{c}\text { Diagnosed Culture } \\
\text { cases } \\
\text { No. (\%) }\end{array}$ \\
\hline IFM & $72(72 \%)$ & $22(30.5 \%)$ \\
IFM,D & $22(22 \%)$ & $18(81.8 \%)$ \\
IFM,U & $2(2 \%)$ & $2(100 \%)$ \\
IFM,D,U & $2(2 \%)$ & $2(100 \%)$ \\
IFM,F & $1(1 \%)$ & $0(0 \%)$ \\
IFM,D,U,F & $1(1 \%)$ & $1(100 \%)$ \\
\hline
\end{tabular}

IFM (Increase Frequency micturation),D (Dysurea), U (Urgency), F (Fever)

Of the total suspected cases, $83.1 \%$ were urine culture positive and had pus cell counts (1-5/HPF). However, 
cases which have more than 5 pus cells/HPF were all culture positives (Table 3 ).

\begin{tabular}{|c|c|c|}
\hline Pus cell/HPF & $\begin{array}{c}\text { Total Suspected } \\
\text { cases } \\
\text { No. (\%) }\end{array}$ & $\begin{array}{c}\text { Culture positive } \\
\text { cases } \\
\text { No. (\%) }\end{array}$ \\
\hline 0 & $2(2 \%)$ & $0(0 \%)$ \\
\hline $0-1$ & $60(60 \%)$ & 13 (21.7\%) \\
\hline $1-5$ & 32 (32\%) & 26 (81.3\%) \\
\hline $5-10$ & $6(6 \%)$ & $6(100 \%)$ \\
\hline
\end{tabular}

Samples which showed Nitrite test positive i.e. 17 (37.7\%) were all culture positives i.e. if the patient has nitrite positive result, it was sure that his urine was infected with Gram negative bacteria. This shows the positive relationship exists between the Nitrite test and culture positive for the member of enterobacteriaceae family (Table 4 and 5).

Table 4. Comparison between the results of Nitrite test and Culture

\begin{tabular}{|cccc|}
\hline & $\begin{array}{c}\text { Culture } \\
\text { positive }\end{array}$ & $\begin{array}{c}\text { Culture } \\
\text { negative }\end{array}$ & Total \\
\hline Nitrite positive & 17 & 0 & 17 \\
Nitrite negative & 28 & 55 & 83 \\
Total & 45 & 55 & 100 \\
\hline \hline
\end{tabular}

\begin{tabular}{|c|c|c|c|c|}
\hline \multirow{2}{*}{ Organism } & \multirow{2}{*}{ Sensitivity } & \multirow{2}{*}{ Specificity } & \multicolumn{2}{|c|}{ Predictive values } \\
\hline & & & Positive & Negative \\
\hline $\begin{array}{l}\text { Enterobac- } \\
\text { teriaceae }\end{array}$ & $70.8 \%$ & $100 \%$ & $100 \%$ & $91.5 \%$ \\
\hline E. coli & $100 \%$ & $96.6 \%$ & $82.3 \%$ & $100 \%$ \\
\hline
\end{tabular}

In total 45 culture cases, 11 species of Gram positive and Gram negative bacteria belonging to 10 genera were isolated from urine samples. Among that, 25 (55.5\%) cases were by Gram negative bacteria including Escherichia coli (14), Klebsiella oxytoca (4). Besides, Staphylococcus aureus (11) and Staphylococcus saprophyticus (8) were the common etiological agent of UTI in pregnant women due to Gram positive bacteria.

Of nine antibiotics used in vitro sensitivity test, Amikacin was the most effective followed by others (Figure 1 ).

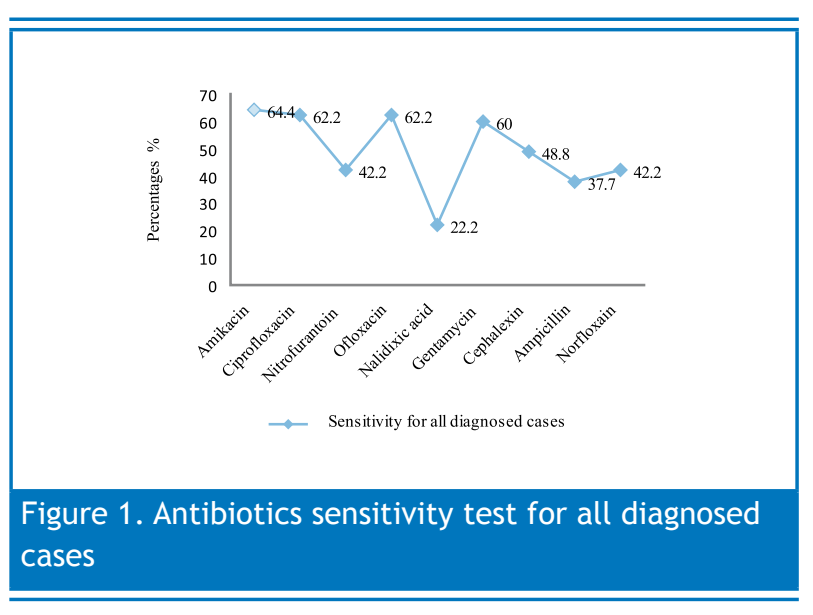

Amikacin was highly effective against Gram-negative bacteria followed by other antibiotics. Similarly, Gentamycin was highly effective against Gram positive followed by other antibiotics (Figure 2).

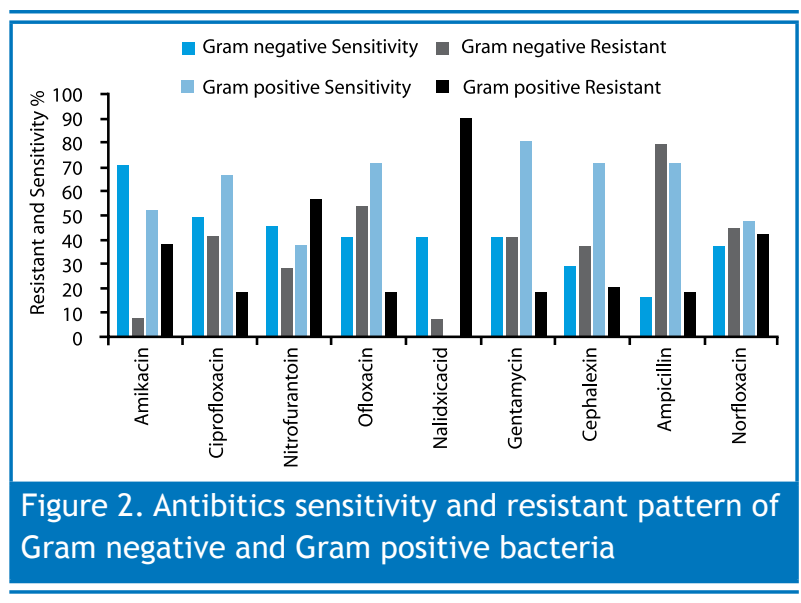

Of the $E$. coli isolates, $64.2 \%$ were effective to Amikacin, followed by other antibiotics. Similarly, Gentamycin was the most effective i.e. 20 (100\%) towards Staphylococcus aureus followed by other antibiotics (Figure 3).

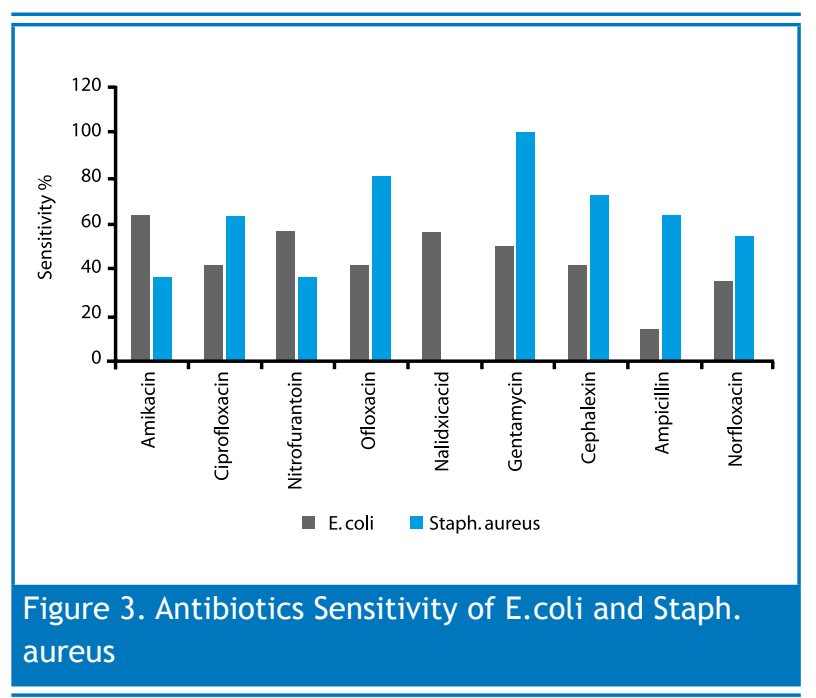


Urinary Tract Infection in Pregnancy and Its Correlation with Nitrite Test

\section{DISCUSSION}

UTIs are very common during pregnancy. Escherichia coli is the most common pathogen isolated from pregnant women. ${ }^{8}$ In the present study $E$. coli found as $31.1 \%$ followed by Staphylococcus aureus, Staphylococcus saprophyticus, Klebsiella oxytica which, however, is still the dominant organism responsible for UTI and a study conducted by Santosh JF et al. ${ }^{9}$ has also stated that the microorganism frequently isolated organisms associated with first infection of UTI was always been and is coliform bacilli followed by Staphylococcus spp. Similar type of result was found by Latham et a ${ }^{10}$ with $60 \%$ of infection by $E$. coli, $30 \%$ by Staphylococcus saprophyticus and $10 \%$ by Proteus mirabilis. Similarly, Pandey ${ }^{11}$ has shown same type of result i.e. E. coli $(35.4 \%)$ followed by COPS (22.3\%) and CONS (saprophyticus) (18.8\%) equal percentage of Enterbacter spp. and Klebsiella oxytoca i.e. $2.1 \%$. He also stated that the microorganism frequently isolated organisms associated with first infection of UTI was always been and is coliform bacilli followed by Staphylococcus spp.

The nitrite test is highly sensitive and specific when properly used in first morning urines. Its efficiency was found $90 \%$ in 1000 women with no false positive. ${ }^{4}$ Our finding also showed that Samples which were nitrite positive were all culture positive. The Sensitivity, Specificity, Positive and Negative predictive values of nitrite test in relation to Enterobacteriaceae were $70.8 \%, 100 \%, 100 \%$ and $91.5 \%$ respectively where as Sensitivity, Specificity, Positive and Negative predictive value of nitrite test in relation to Escherichia coli were $100 \%, 96.6 \%, 82.3 \%$, and $100 \%$, respectively. However, Regmi, $2003^{12}$ reported that the Sensitivity of nitrite test in relation to Enterobacteriaceae and $E$. coli were $58.7 \%$ and $50.9 \%$ respectively with specificity $99.5 \%$. From our finding we can say that the nitrite test with pus cell ( $>5$ HPF) appears to be very useful marker for bacterial UTI and is more useful in district laboratories where culture facilities are rare.

The antibiotic sensitivity patterns of isolates were variable. None of the tested antibiotics were 100\% sensitive for isolates. Amikacin was the most effective antibiotics, 29(64.4\%) against Gram-negative organism followed by Ciprofloxacin and Nitrofurantoin where as Gentamycin, 16 (80\%) was effective against Gram positive bacteria followed by Cephalexin and Ofloxacin. Similarly, Ampicillin, 20 (80\%) was found highly resistant against Gram-negative bacteria followed by Ofloxacin and Norfloxacin.

\section{CONCLUSIONS}

Escherichia coli is common pathogen isolated form pregnant women. Although diagnosis of UTI is confirmed by culture method the combination of Nitrite test with pyuria appears to be very useful markers for bacterial UTI and is more useful in district laboratories where culture facilities are rare. Since, antibiotics resistant bacterial pathogens were isolated, it can recommend that over use, under use \& misuse of antibiotics must be prohibited. On the basis of in vitro tests Ampicillin was found resistant towards bacterial isolates so it should not be used for the treatment of UTI.

\section{ACKNOWLEDGEMENTS}

I would like to thank my supervisors and all the members of Bacteriology Laboratory, Lumbini Zonal Hospital, Butwal.

\section{REFERENCES}

1. Whalley PJ, Martin FG, Peters PC. Significance of asymptomatic bacteriuria detected during pregnancy. JAMA. 1965 Sep 13;193:879-81.

2. Kass EH. Maternal urinary tract infection. J New York State Med. $1962 ; 2822-26$

3. Chung $\mathrm{PK}$, Hall MH. Antenatal prediction of urinary tract infection in pregnancy. Br J Obstet Gynaecol. 1982 Jan;89:8-11.

4. Robertson AW, Duff P. The nitrite and leucocyte esterase tests for the evaluation of asymptomatic bacteriuria in obstetric patients. Obstet Gynecol. 1988 Jun;71(6 Pt 1);878-81.

5. Conolly A, Thorp JM. Urinary tract infections in pregnancy. Urol Clin North Am. 1999; 26:779-87.

6. Delzell JE Jr, Lefevre ML. Urinary tract infections during pregnancy. Am Fam Physician. 2000 Feb 1;61(3):713-21.

7. Johnson M. Urinary tract infections in women. American Family Physician. 1990;41:565-70.

8. Ovalle A, Levancini M. Urinary tract infection in pregnancy. Curr Opin Urol. 2001 Jan;11(1):55-9.

9. Santosh JFM, Ribeiro RM, Rossi P, Haddad MJ, Guidi HGC, Pacetta AM, et al. Urinary tract infection in pregnant women. J. International Urogynecology. 2002;13:204-9.

10. Latham RH, Running K, Stamm WE. Urinary tract infection in young adult women caused by Staphylococcus saprophyticus. JAMA. 1983 Dec 9;250(22):3063-6.

11. Pandey RA, Pokharel BM. Hospital based study of urinary tract infection among women visiting antenatal clinic of Tribhuvan University Teaching Hospital. A dissertation submitted to central department of Microbiology, TU Kathmandu, Nepal, 2002.

12. Regmi S, Ghimere P. Evaluation of nitrite test in detetecting urinary tract infectión. A dissertation submitted to central department of Microbiology, TU Kathmandu, Nepal, 2003. 